\title{
COMPARISON OF THE FRACTURE RESISTANCE OF ENDODONTICALLY TREATED TEETH RESTORED WITH PREFABRICATED POSTS AND COMPOSITE RESIN CORES WITH DIFFERENT POST LENGTHS
}

\author{
Accácio Lins do VALLE ${ }^{1}$, Jefferson Ricardo PEREIRA² ${ }^{2}$ Fábio Kenji SHIRATORI ${ }^{3}$, \\ Luiz Fernando PEGORARO ${ }^{1}$, Gerson BONFANTE
}

\begin{abstract}
1-DDS, MSc, PhD, Associate Professor, Department of Prosthodontics, Bauru School of Dentistry, University of São Paulo.
2- DDS, MSc, Graduate student (PhD degree), Department of Prosthodontics, Bauru School of Dentistry, University of São Paulo.

3- DDS, Graduate student, Department of Prosthodontics, Bauru School of Dentistry, University of São Paulo.
\end{abstract}

Corresponding address: Jefferson Ricardo Pereira - Rua Charles Lindemberg, 1-45 apart. 154 - Jardim Europa - Cep.: 17017-471 Bauru-SP, Brasil phone \# 551432274857 - e-mail: jeffripe@rocketmail.com

Received: December 20, 2005 - Modification: April 18, 2006 - Accepted: November 16, 2006

\begin{abstract}
Q

bjective: This study evaluated the fracture strengths of endodontically treated teeth restored with prefabricated posts with different post lengths. Material and methods. Thirty freshly extracted canines were endodontically treated. They were randomly divided into groups of 10 teeth and prepared according to 3 experimental protocols, as follows; Group 1/3 PP: teeth restored with prefabricated post and composite resin core (Z250) with post length of 5.0mm; Group 1/2 PP and Group 2/3 PP: teeth restored with prefabricated post and composite resin core (Z250) with different combinations of post length of $7.5 \mathrm{~mm}$ and $10 \mathrm{~mm}$, respectively. All teeth were restored with full metal crowns. The fracture resistance $(\mathrm{N})$ was measured in a universal testing machine (crosshead speed $0.5 \mathrm{~mm} / \mathrm{min}$ ) at 45 degrees to the tooth long axis until failure. Data were analyzed by one-way analysis of variance $(\alpha=.05)$. Results. The one-way analysis of variance demonstrated no significant difference among the different post lengths $(\mathrm{P}>.05)$ (Groups $1 / 3 \mathrm{PP}=405.4 \mathrm{~N}, 1 / 2 \mathrm{PP}=395.6 \mathrm{~N}, 2 / 3 \mathrm{PP}=393.8 \mathrm{~N})$. Failures occurred mainly due to core fracture. Conclusion. The results of this study showed that an increased post length in teeth restored with prefabricated posts did not significantly increase the fracture resistance of endodontically treated teeth.
\end{abstract}

Uniterms: Post and core technique; Composite resins; Fracture stress.

\section{INTRODUCTION}

The restoration of non-vital teeth is an important aspect of dental practice that involves a range of treatment options of variable complexity. Numerous techniques using post and core restorations have been advocated with criteria for success depending on variations in length ${ }^{4}$ diameter $^{8,26}$, shape and surface configuration ${ }^{22,24}$, and materials and techniques used for their construction ${ }^{8,20}$.

The likelihood of survival of a pulpless tooth is directly related to the quantity and quality of the remaining dental tissue $^{27}$. A post is usually placed in an attempt to strengthen the tooth ${ }^{3,9,13}$. However, "in vitro" and "in vivo" studies have demonstrated that posts do not reinforce endodontically treated teeth ${ }^{14,20,23,30}$. Posts are required to supporting a core foundation when there is insufficient remaining structure of clinical crown ${ }^{14,20,23,30}$.

Although cast post and core restorations are the choice for endodontically treated teeth when the coronal tooth structure is missing, prefabricated post systems are popular because they save time and can provide satisfactory results ${ }^{16,25,28}$. Despite the efforts to reinforce endodontically treated teeth with internal posts and cores, tooth fractures continue to occur ${ }^{13}$. Some authors ${ }^{2,12}$ demonstrated that roots restored with cast posts exhibited significantly higher internal stresses than prefabricated posts. With recent improvements in the bonding of composite resins to dentin, true internal retention became available $\mathrm{e}^{1,5,6,14,19-21}$.

The length of a post relative to root length is an unresolved problem in post design ${ }^{10,11}$. Laboratory studies have shown that increasing the length of the post results in a more favorable stress distribution along the $\operatorname{root}^{15,19,24}$ and an increased post length improves the resistance of the restored tooth to fracture ${ }^{29}$. Furthermore, Sorensen and Martinoff ${ }^{23}$ demonstrated that an increased survival rate has been correlated with increasing post length. However, a study conducted by Burns, et al. ${ }^{7}$ showed a minimal difference in stress distribution between varying post lengths. Similarly, 
Isidor, et al. ${ }^{17}$ observed that an increase in post length does not necessarily increase the fracture resistance of the tooth.

It is important to notice that it may not always be possible to use a long post, especially when the remaining root is short or curved. Kvist, et al. ${ }^{18}$ and Mattison, et al. ${ }^{21}$ suggested that it is important to preserve 3 to $5 \mathrm{~mm}$ of apical gutta-percha to maintain the apical seal.

The purpose of this study was to evaluate the fracture resistance of endodontically treated teeth restored with prefabricated posts with different post lengths. The null hypothesis of the present study was that the different post lengths would not influence the fracture strength of endodontically treated teeth.

\section{MATERIALAND METHODS}

Thirty recently extracted maxillary canines with similar root sizes (between $15 \mathrm{~mm}$ and $16 \mathrm{~mm}$ ) measured with a millimeter ruler from the apex to the cementoenamel junction (CEJ) were selected from 47 maxillary canines extracted for periodontal reasons. After the roots were scaled with periodontal curettes and water, they were sectioned with double-faced diamond discs (KG Sorensen, Barueri, SP, Brazil) to a standardized length of $15 \mathrm{~mm}$. The teeth were stored in distilled water at $37^{\circ} \mathrm{C}$. The inclusion criteria for tooth selection were teeth without root surface carious lesions or fissures and not previously subjected to endodontic therapy. Each canal was prepared at $1 \mathrm{~mm}$ of the radiographic apex with a standard master apical file \#20 (Dentsply Maillefer, Ballaigues, Switzerland). Master apical files (Dentsply Maillefer, Ballaigues, Switzerland) 3 sizes larger (\#25, \#30, and \#35) than the initial instrument were used. The root canal for each tooth was instrumented with a conventional step-back technique to an International Standardization Organization (ISO) file \#35 (Dentsply Maillefer, Ballaigues, Switzerland) at the apical constriction. The canals were irrigated with $2.5 \%$ sodium hypochlorite solution (Asfer Industrial Química, São Paulo, SP, Brazil) throughout the preparation and dried with paper points (Tamari, Tamariman Industrial LTDA, Macaçaruru, AM, Brazil). Each canal was obturated by lateral condensation using gutta-percha cones (Tamari, Tamariman Industrial LTDA, Macaçaruru, AM, Brazil) and an ISO 35 primary guttapercha master cone (Tamari, Tamariman Industrial LTDA, Macaçaruru, AM, Brazil). Root canal cement (Endometazone Ivory; Septodont Brasil, Barueri, SP, Brazil) was used as sealer. Afterwards, the teeth were randomly divided into 3 groups of 10 teeth each. Randomization was accomplished by drawing lots.

Post preparations were made with a \#5 drill (Largo; Dentsply Maillefer, Ballaigus, Switzerland) to remove $5 \mathrm{~mm}$ of gutta-percha apical to the cementoenamel junction (CEJ) from each filled canal in Group 1/3 PP (1/3 of root length), $7.5 \mathrm{~mm}$ in Group $1 / 2 \mathrm{PP}(1 / 2$ of root length) and $10 \mathrm{~mm}$ in Group 2/3 PP (2/3 of root length).

In all groups, the root canals were restored with prefabricated stainless steel, parallel-sided, serrated posts with a tapered end (number 5317, Screw-Post, Euro-Post Anthogyr S.A., Sallanches, France). The posts were cemented with glass ionomer (Rely X, 3M Dental Products Division St. Paul-Minessota, USA). The cement was placed on the post, which was then seated under $9 \mathrm{~kg}$ of pressure during 10 minutes. The dentin was etched with $37 \%$ phosphoric acid and a bonding agent (Primer-Bond 2.1, Dentsply Ind. Com, Petropolis, Brazil) was placed on it as recommended by the manufacturer. Cores were fabricated in a standardized form using a core-forming matrix (TDV Dental, Pomerode, SC, Brazil), and a composite resin material (Z250 - 3M Dental Products Division St. Paul, Minn) $)^{22}$. The composite resin was placed using the incremental technique. Five increments of the composite resin were applied, each requiring 40 seconds of composite light curing to complete the coronal core. A light-curing device (Ultraled, Dabi Atlante, Ribeirão Preto, SP, Brazil) was used to light cure the composite resin specimens. The light curing tip was positioned at $2 \mathrm{~cm}$ from the specimens on top of the core ${ }^{22}$. Afterwards, each specimen was once again stored in distilled water at $37^{\circ} \mathrm{C}$.

All specimens were prepared with a diamond bur (number 3216) (KG Sorensen, Barueri, SP, Brazil) at high-speed with water spray (Super Torque 625 Autofix, Kavo do Brasil Ind. Com. LTDA, Joinville, SC, Brazil). They were prepared for an ideal crown preparation (1.5-mm facial reduction with a chamfer finish line and $0.5-\mathrm{mm}$ chamfered lingual reduction). All finish lines for all specimens and groups were placed at the level of the CEJ. An impression of the tooth was made using a vinyl polysiloxane impression material (Aquasil, Dentsply, Konstanz, Germany) prior to preparation and was used to fabricate the wax pattern. Wax (Kerr Corporation, CA, USA) was then poured into the impression and the tooth inserted into it; after the wax cooled, the impression was removed and the margins were adjusted. The wax patterns were sprued, invested (Cristobalite, Whip-Mix Corporation, Louisville, Ky, USA) and cast in Ni-Cr alloy (Durabond, São Paulo, Brazil). Crowns were luted to the teeth with the glass ionomer cement (Rely X, 3M Dental Products Division St. Paul, Minn., USA).

All specimens were embedded in acrylic resin (Clássico, Artigos Odontológicos S/A, São Paulo, SP, Brazil) poured into molds made of the same material $(30-\mathrm{mm}$ height, and diameter of $22 \mathrm{~mm}$ and an internal space, located in the center of the mold, with diameter of $10 \mathrm{~mm}$ and $20 \mathrm{~mm}$ in height). The teeth were embedded along their long axes using a dental surveyor (Bio Art Equipamentos Odontológicos Ltda, São Carlos, SP, Brazil) and placed in a cool water bath during curing of the resin.

Each specimen was fixed in a special apparatus (fabricated by the authors) that allowed it to be positioned at 45 degrees to the buccal/lingual long axis ${ }^{22}$. The specimens were subjected to loading at this direction in a universal testing machine (Kratus K2000 MP, Dinamometros KRATOS Ltda, SP, Brazil) (Figure 1). A crosshead speed of $0.5 \mathrm{~mm} / \mathrm{min}$ was applied until failure. The load was measured in Newtons (N). Failure was defined as fracture of the core material with displacement from the post head, or when fracture affected 
the core or the tooth.

Data were analyzed by one-way analysis of variance (ANOVA) to determine the overall differences among the means of the test groups and the overall variability within the test groups $(\alpha=.05)$.

\section{RESULTS}

Table 1 summarizes the mean fracture resistance for the 3 tests groups. ANOVA showed there was no significant difference among groups $(P>.05)$. In all groups, failures were mainly due to core fracture $(1 / 3 \mathrm{PP}-100 \% ; 1 / 2 \mathrm{PP}-100 \%, 2 /$ 3 PP-90\%).

\section{DISCUSSION}

The results of the present study accepted the null hypothesis because they showed that the increase in post length in teeth restored with prefabricated posts and composite resin core did not significantly increase the fracture resistance of endodontically treated teeth.

In the present study, the best results were obtained with the shortest posts; the longest posts gave the worst results. In the test models, preparation for this post length may have weakened the root considerably more than the reinforcement provided by the cemented post. Leary, et al. ${ }^{19}$ showed that preparation for a post weakens the root considerably. In other words, the use of a post, when preparation of the root to receive the post removed a lot of

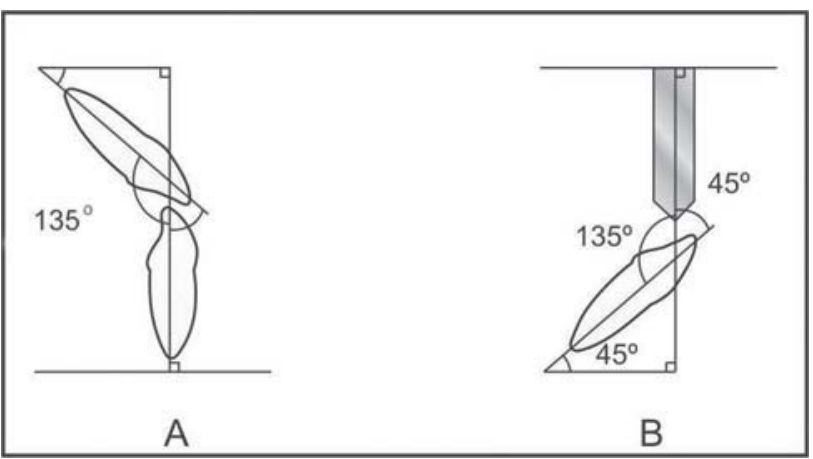

FIGURE 1- The specimens were subjected to load at 45 degrees on a universal testing machine (crosshead speed $0.5 \mathrm{~mm} / \mathrm{min}$ ) (Kratus K2000 MP, Dinamometros KRATUS Ltda, São Paulo, SP, Brazil)

TABLE 1- Resistance to failure values of test specimens, means $(\mathrm{N})$ of test groups and standard deviations

\begin{tabular}{lll} 
Groups & Mean (N) & SD \\
\hline 2/3 PP & 393.8 & $(81.1)$ \\
$1 / 2 \mathrm{PP}$ & 395.6 & $(57.8)$ \\
$1 / 3 \mathrm{PP}$ & 405.4 & $(71.4)$ \\
\hline
\end{tabular}

dentinal structure, may weaken the tooth more than reinforce it. This may explain why increasing the length of the post did not consistently increase the fracture resistance of roots in the present study. The results of this study are similar to those of Isidor, et al. ${ }^{17}$, who showed that the increase in post length when the tooth was restored with prefabricated posts did not increase the fracture resistance of endodontically treated teeth. On the other hand, these findings are not in agreement with those of Standlee, et al. ${ }^{24}$ and Holmes, et al. ${ }^{15}$, who showed that increasing the post length in the tooth results in a more favorable stress distribution along the post, leading to higher fracture resistance.

Analysis of the fracture mode of specimens showed that the most common cause of failure was fracture of the restorative material. The results of this study are in agreement with those of Bowen and $\mathrm{Colb}^{6}$, who concluded that composite resin fracture can occur at a lower force than that required to yield root fracture. According to Abdalla and Alhadainy ${ }^{1}$ and Pereira, et al. ${ }^{22}$, the fracture of composite resin core when occlusal force is applied may be a positive occurrence because it could be protective to the supporting root and, consequently, the use of prefabricated posts and composite resin cores is a viable technique for endodontically treated teeth ${ }^{2,22,25,28}$.

The limitations of this study include its "in vitro" nature, which did not replicate the oral conditions; also, a single load test was used to investigate the fracture resistance of endodontically treated teeth. For more meaningful results, future studies should incorporate thermal cycling of specimens and fatigue loading.

\section{CONCLUSION}

Within the limits of this "in vitro" study, the following conclusions were drawn:

1. No statistically significant difference was found in the fracture resistance of endodontically treated teeth among the means of the three groups.

2. The prefabricated post-and-composite resin core groups showed crown composite resin core failure before occurrence of root fracture.

\section{REFERENCES}

1- Abdalla AI, Alhadainy HA. 2-years clinical evaluation of class I posterior composites. Am J Dent. 1996;9:150-2.

2- Assif D, Oren E, Marshak BL, Aviv I. Photoelastic analysis of stress transfer by endodontically treated teeth to the supporting structure using different restorative techniques. J Prosthet Dent. 1989;61:676-8.

3- Assif D, Gorfil C. Biomechanical considerations in restoring endodontically treated teeth. J Prosthet Dent. 1994;71:565-7.

4- Baraban DJ. The restoration of pulpless teeth. Dent Clin N Am. 1967;12:633-53. 
5- Bex RT, Parker MW, Judkins JT, Pelleu GB. Effect of dentinal bonded resin post-core preparations on resístanse to vertical fracture J Prosthet Dent. 1992;67:768-72

6- Bowen RL, Cobb EN. A method for bonding to dentin and enamel. J Am Dent Assoc. 1983;107:1070-6.

7. Burns DA, Krauser WR, Douglas HB, Burns DR. Stress distribution surrounding endodontic posts. J Prosthet Dent. 1990;64:412-8.

8- Caputo AA, Standee JP. Pins and posts-why, when, and how. Dent Clin North Am. 1976;20:299-311.

9- Cohen BL, Pagnillo M, Condos S, Deustsch AS. Comparison of torsional forces at failure for seven endodontic post systems. J Prosthet Dent. 1996;74:350-7.

10- Fernandes AS, Shetty S, Coutinho I. Factors determining post selection: a literature rewiew. J Prosthet Dent. 2003;90:556-62.

11- Fernandes AS, Dessai GS. Factors affecting the fracture resistance of post-core reconstructed teeth: a review. Int J Prosthodont. $2001 ; 14: 355-63$

12- Fraga RC, Chaves GSB, Mello JF, Siqueira JR. Fracture resistance of endodontically treated roots after restoration. J Oral Rehabil 1998;25:809-13.

13- Gutmann JL. The dentin-root complex: anatomic and biologic considerations in restoring endodontically treated teeth. J Prosthet Dent. 1992;67:458-67

14- Guzy GE, Nicholls JI. "In vitro" comparison of intact endodontically treated teeth with and without endo-post reinforcement. J Prosthet Dent. 1979;42:39-44.

15- Holmes DC, Arnold AM, Leary JM. Influence of post dimentions on stress distribution in dentin. J Prosthet Dent. 1996;75:140-7.

16- Hopwood WA, Wilson NH. Clinical assessment of split-shank post system in permanent molar and pre-molar teeth. Quintessence Int. 1990;21:907-11

17- Isidor F, Brondum K, Ravnholt G. The influence of post length and crown ferrule on the resistance to cyclic loading of bovine teeth prefabricated titanium post. Int J Prosthodont. 1999;12:79-82.

18- Kvist T, Rydin E, Reit C. The relative frequency of periapical lesions in teeth with root canal -retained posts. J Endod. 1989;15:578 80

19- Leary JM, Aquilino, SA, Svare CW. An evaluation of post length within the elastic limits of dentin. J Prosthet Dent. 1987;57:277-81.

20- Lovdahl PE, Nicholls JI. Pin retained amalgam cores vs. cast gold post and cores. J Prosthet Dent. 1977;38:507-14.

21- Mattison GD, Delivanis PD, Thacker RW, Hassel KL. Effect of post preparation on the apical seal. J Prosthet Dent. 1984;51:785-9.

22- Pereira JR, Ornelas F, Conti PC, Valle AL. Effect of a crown ferrule on the resistance of endodontically treated teeth restored with prefabricated posts. J Prosthet Dent. 2006;95:50-4.

23- Sorensen JA, Martinoff JT. Intracoronal reinforcement and coronal coverage: a study of endodontically treated teeth. J Prosthet Dent. 1984;51:780-4.

24- Standlee JP, Caputo AA, Collard EW, Pollack MII. Analisis of stress distribuition by endodontic posts. Oral Surg Oral Med Oral Pathol. 1972;33:952-60

25- Stockton LW. Factors affecting retention of post systems: a literature review. J Prosthet Dent. 1999;81:380-5.
26- Tilk MA, Lommel TJ, Gerstein II. A study of mandibular and maxillary root widths to determine dowel size. J Endod. 1979;7:7082

27- Tjan AHL, Whang SB. Resistance to root fracture of post channels with various thicknesses of buccal dentin walls. J Prosthet Dent. 1985;53:496-500

28- Torbjorner A, Fransson B. A literature review on the prosthetic treatement of structurally compromised teeth. Int J Prosthodont. 2004; 17:369-76.

29- Trabert KC, Caputo AA, Abou Rass M. Tooth fracture - a comparison of endodontic and restorative treatment. J Endod. $1978 ; 4: 341-5$

30.-Trope M, Maltz DO, Tronstad L. Resistance to fracture of restored endodontically treated teeth. Endod Dent Traumatol. $1985 ; 1: 108-11$. 